\title{
Effect of intravenous Deferoxamine concomitant use with blood transfusion on serum ferritin in thalassemia major patients
}

\author{
Afshin Fathi, Firouz Amani, Samira Araghchin, Esmaeil Farzaneh*
}

Faculty of Medicine, Ardabil University of Medical Science, Ardabil, Iran

Received: 07 December 2016

Revised: 10 December 2016

Accepted: 28 December 2016

*Correspondence to:

Dr. Esmaeil Farzaneh,

Email:

dr.farzaneh.milad@gmail.com

Copyright: (C) the author(s), publisher and licensee Medip Academy. This is an openaccess article distributed under the terms of the Creative Commons Attribution NonCommercial License, which permits unrestricted noncommercial use, distribution, and reproduction in any medium, provided the original work is properly cited.

\begin{abstract}
Background: Subcutaneous Deferoxamineis often not tolerated by patients and its rejection leads to iron overload with its complications. So, other methods with better toleration and reduction of Deferoxamine consumption are necessary. The present study aimed to evaluate the effect of intravenous Deferoxamine infusion during blood transfusion on serum ferritin (SF) in thalassemia major patients.

Methods: In a retrospective cross-sectional study, thirty four patients with $\beta$ thalassemia major treated with monthly blood transfusion at Bu-Ali hospital in Ardabil city from April 2013 to April 2014, were selected and followed for six months. The mean SF rate and the needed subcutaneous Deferoxamine rates before intervention were considered as baseline. All patients received intravenous Deferoxamine concomitant with their routine monthly blood transfusion for six months. After six months mean values for ferritin, subcutaneous Deferoxamine were compared with baseline values. Collected data were analyzed using t-test and paired t-test by SPSS, version $18 . P<0.05$ was considered as significant.

Results: Compared with baseline, the subcutaneous Deferoxamine rate and ferritin level have been decreased significantly after intervention.

Conclusions: Intravenous Deferoxamine concomitant use with routine monthly blood transfusion in thalassemia major patients can lead to decreasing of ferritin level. With this method, patient care could be improved, health care costs and complications of treatment effectively reduced.
\end{abstract}

Keywords: Beta-thalassemia, Blood transfusion, Deferoxamine

\section{INTRODUCTION}

Thalassaemia major is a genetic disease characterized by a reduced ability to produce hemoglobin. ${ }^{1}$ BetaThalassemia, originally named Cooley anemia, is an inherited blood disease that are created by effective mutations in the hemoglobin synthesis. ${ }^{2}$ Various types of thalassemia are inherited anemia caused by mutations at the globin gene loci on chromosomes 16 and 11, affecting the production of alpha or beta-globin protein, respectively. ${ }^{2}$ This is the most common hereditary anemia in the world and prevalent in Africa, Mediterranean countries and Asia. ${ }^{1-3}$ In Iran in average $4.5 \%$ of population is beta-thalassemia carriers and its incidence rate indifferent provincesvariesbetween $1-10 \%{ }^{4,5}$

Thalassemiaisone of the world's most extensive genetic diseases that affect about $5 \%$ of world population. Beta- thalassemia is divided into three main groups: thalassemia major, thalassemia intermediate and minor. ${ }^{5-7}$ Long duration transfusion of blood is the best treatment for major thalassemia patients. ${ }^{8}$ Despite the problems of anemia improved after the presentation of regimes hyper transfusion, hemosiderosis of the thalassemia disease and its treatment is one of the most limiting factors in these patients. Injecting too much blood can lead to the accumulation of iron in the body and non-excretion of excess iron leads to serious complications. ${ }^{9,10}$ Symptoms of iron overload in these patients occur as deposition in the heart and endocrine glands in the form of diabetes mellitus, hypothyroidism, hypoparathyroidism, growth retardation, hypogonadism, and finally liver fibrosis and cirrhosis. $^{11,12}$

Iron overload complications in different organs, is one of the main problems in patients with thalassemia major 
treated with repeated transfusions. Therefore new therapies are sought to decrease these complications, but an appropriate treatment strategy is not defined yet. Iron chelating therapy begins when the patient has received 10-20 blood transfusions or serum ferritin level has reached $>1000 \mathrm{ng} / \mathrm{ml}$.

Subcutaneous Deferoxamine as chelating agent is often not tolerated by patients and rejecting its application causes iron overload followed by complications. So, alternative methods to achieve better toleration and lower Deferoxamine doses are desirable.

It was shown that early treatment of major thalassemia patients with Deferoxamine can improve prognosis and quality of life of patients and reduce the incidence of major complications due to iron overload (e.g., heart failure). The benefits of long-term treatment with Deferoxamine in increasing survival and reducing cardiac complications in patients with transfusion-dependent beta thalassemia have been documented well. ${ }^{13}$

Deferoxamine is currently recognized as a golden standard in treatment of iron. Until now many treatment regimens using Deferoxamine are introduced but results are still controversial and from all suggested methods the concomitant use of intravenous Deferoxamine and blood seem to be the best. ${ }^{14}$ There are many evidences for importance of concomitant use of intravenous Deferoxamine in decreasing morbidity and mortality of the affected patients. ${ }^{13}$ In this study we used this regimen which is not used routinely in thalassemia clinics. The present study aimed to investigate the effect of concomitant administration of intravenous Deferoxamine with blood transfusion on serum ferritin level in thalassemia major patients.

\section{METHODS}

In this retrospective cross-sectional study, records of 34 patients with beta-thalassemia major at Bu-Ali hospital in Ardabil city, who were referred to receive regular blood transfusions in April 2013 to April 2014, were studied. 15 $(45.7 \%)$ of the patients were males. The mean age of patients was $20.1 \pm 5.7$ (range $8-28$ ) years. All the patients were over 8 years old and transfusion-dependent using Deferoxamine as iron-chelating agent, some with poor compliance. The diagnosis had been made according to hemoglobin electrophoresis results and complete blood count. The study protocol was approved by the Ethics Committee of Ardabil University of Medical Sciences (code ARUMS1013). Informed written consent was obtained from all parents. The inclusion criteria included the absence of abnormalities in organs and exclusion criteria included provencirrhosis or having complications due to Deferoxamine such as swelling of the skin - skin rash - a rash and anaphylactic reactions.

The mean amount of ferritin and subcutaneous Deferoxamin before start of intervention was checked and considered as the baseline in beta-thalassemia major patients who had been treated with monthly routine blood transfusions. All patients received intravenous Deferoxamine concomitant with monthly blood transfusion for six months. After six months the mean values of ferritin, subcutaneous Deferoxamine were compared with baseline.

Deferoxamine was used as $500 \mathrm{mg}$ per $5 \mathrm{~kg}$ of body weight infusion during 8 hours. In patients $<10$ years old $50 \mathrm{mg}$ and over 10 years old $100 \mathrm{mg}$ Vitamin $\mathrm{C}$ was administered.

Necessary information including demographic data, hemoglobin levels, rate of Deferoxamine and its side effects and history of splenectomy collected for all patients by checklist in follow up period.

The normality of data was checked by K-S test in SPSS.18. The results were expressed as mean \pm SD. We used t-test and paired t-test to compare the mean values between the two groups with baseline three and six months after intervention. The $\mathrm{P}<0.05$ was considered as significant for all test results.

\section{RESULTS}

The mean value of ferritin in baseline was $3156.3 \pm 403.6$ $\mu \mathrm{g} / \mathrm{dl}$ which significantly decreased to $2790.2 \pm 367.8$ three months after study begin $(\mathrm{P}=0.04)$. But the difference between ferritin six months after it compared with baseline was not statistically significant (Figure 1).

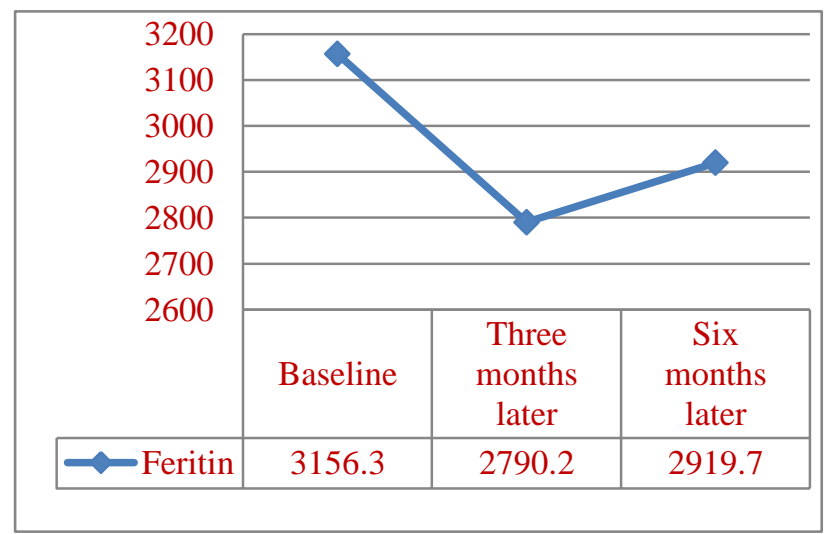

Figure 1: The amount of ferritin in baseline, three and six months after study begin.

The mean value of subcutaneous Deferoxamine three months after intervention was $34.4 \pm 5.8$ and in baseline it was $75.4 \pm 12.9$, The rate of reduction was statistically significant $(\mathrm{P}=0.002)$.

The mean value of subcutaneous Deferoxamine six months after intervention was $21 \pm 5$ and in baseline it was $75.4 \pm 12.9$. The rate of reduction was statistically significant $(\mathrm{P}=0.001)$. 
The reductionin rate of subcutaneous Deferoxamine three and six months after study begins compared with baseline were $54.4 \%$ and $73.2 \%$; respectively. In this study, the mean value of Deferoxamine in three months after study begins was $32.4 \pm 9.2$ and in baseline it was $85.9 \pm 17.4$ (Figure 2). There was a significant reduction in the rate of Deferoxamine compared to baseline $(\mathrm{P}=0.001)$.

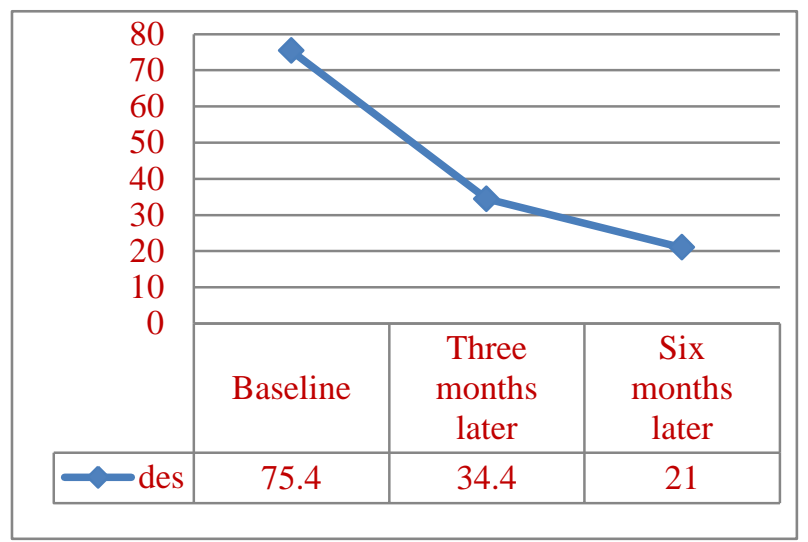

Figure 2: the mean value of used subcutaneous Deferoxamine amount in baseline three and six months after study begin.

In evaluation the effect of Splenectomy on subcutaneous Deferoxamine in three and six months after study begin, results showed that there was a significant reduction in the rate of subcutaneous Deferoxamine in patients who were Splenectomized $(\mathrm{P}=0.025, \mathrm{P}=0.033)$.

Also, in patients with no splenectomy there was a significant reduction in subcutaneous Deferoxamine three and six months after intervention compared with baseline $(\mathrm{P}=0.002, \mathrm{P}=0.024)$.

In patients with Splenectomy, there was a significant reduction in the rate of ferritin three months after study begin $(\mathrm{P}=0.046)$ but six months after intervention it wasnot significant compared with baseline.

The average values of ferritin amount three and six months after intervention was decreased in male but in female this rate was increased. There wasn't significant relation between two sexes and changing of the ferritin level. The average subcutaneous Deferoxamine reduction rate was 32 and 49 units in male and female three months after intervention but not statistically significant. Also, the average subcutaneous Deferoxamine reduction rate was 42 and 66 units in males and females six months after intervention but not statistically significant.

Results showed that in none of age groups there were significant differences between subcutaneous Deferoxamine and ferritin three and six months after study intervention compared with baseline (Table 1).
Table 1: Changes in ferritin and subcutaneous Deferoxamine amount three and six months after intervention by age groups.

\begin{tabular}{|c|c|c|c|c|}
\hline Differences & $\begin{array}{l}\text { Age } \\
\text { group }\end{array}$ & $\begin{array}{l}\text { Mean } \\
\text { value }\end{array}$ & SD & $\begin{array}{l}\text { P- } \\
\text { value }\end{array}$ \\
\hline \multirow{3}{*}{$\begin{array}{l}\text { Difference between } \\
\text { mean values of } \\
\text { ferritin and baseline } \\
\text { three months after } \\
\text { intervention }\end{array}$} & $7-14$ & -523 & 270 & \multirow{3}{*}{0.43} \\
\hline & $14-21$ & -336 & 702 & \\
\hline & $21-28$ & -298 & 293 & \\
\hline \multirow{3}{*}{$\begin{array}{l}\text { Difference between } \\
\text { mean values of } \\
\text { subcutaneous } \\
\text { Deferoxamine and } \\
\text { baseline three } \\
\text { months after } \\
\text { intervention }\end{array}$} & $7-14$ & -12 & 27.4 & \multirow[b]{3}{*}{0.45} \\
\hline & $14-21$ & -53 & 21.4 & \\
\hline & $21-28$ & -49 & 22.3 & \\
\hline \multirow{5}{*}{$\begin{array}{l}\text { Difference between } \\
\text { mean values of } \\
\text { subcutaneous } \\
\text { Deferoxamine and } \\
\text { baseline six months }\end{array}$} & $7-14$ & -27.6 & 814 & \multirow{5}{*}{0.43} \\
\hline & $14-21$ & -68.4 & 1817 & \\
\hline & $21-28$ & -60.5 & 2116 & \\
\hline & $14-21$ & -7.1 & 7.1 & \\
\hline & $21-28$ & -7.2 & 24.2 & \\
\hline
\end{tabular}

\section{DISCUSSION}

The efficacy of using higher doses of Deferoxamine (more than $10 \mathrm{mg}$ per $\mathrm{kg}$ of body weight per hour) have been studied in various studies and researchers have concluded that higher doses of Deferoxamine, especially in patients with high serum ferritin, compared to the commonly used doses, are more effective in reducing complications and improving patients' quality of life. ${ }^{15,16}$

Cardiac complications due to iron overload lead to $71 \%$ of mortality in major thalassemia patients and currently, Deferoxamine is the only used drug for iron removal in clinical centers. ${ }^{14}$ In our study patients received intravenous Deferoxamine (100 mg per one $\mathrm{kg}$ of body weight) with monthly blood transfusion by infusion during 8 hours and after follow-up period, patients have lower rate of ferritin compared with baseline.

Intravenous administration of Deferoxamine has positive effect on high risk thalassemia major patients and patients with heartproblems. ${ }^{13,17,18}$ Some experts believe that the vitamin $\mathrm{C}$ has useful effect on increasing urinary excretion of iron by Deferoxamine. ${ }^{18}$ Also, in this study $50 \mathrm{mg}$ vit $\mathrm{C}$ for patients younger than 10 years and 100 $\mathrm{mg}$ vit $\mathrm{C}$ for patients over 10 years old was given by orally before Deferoxamine infusion.

According to results, three months after intervention there was a significant reduction in the rate of ferritin compared with baseline values $(\mathrm{P}=0.046)$ but this reduction was not statistically significant six months after intervention which can be due to decreasing arbitrary use of daily subcutaneous Deferoxamine by patients. Some studies reported that the intravenous application of 
Deferoxamine can be effective in improving cardiac function of patients. ${ }^{17-19}$ In our study after intervention the usage of subcutaneous Deferoxamine in average was significantly decreased followed by reduction in the amount of medication side effects and health care costs. ${ }^{20}$ Mashhadi et al showed that the concomitant use of Deferoxamine and Deferiprone was effective in reducing ferritin values but the symptoms such as dysplasia, nausea, joint pain and stiffness were seen in 13-18\% of the patients. ${ }^{19}$

It is noted that none of the patients in our study suffered from acute complication of intravenous Deferoxamine and were not excluded due to complications caused by Deferoxamine in follow up period. It seems that the intravenous Deferoxamine Concominant with Blood Transfusion in thalassemia major patients will be considerable help to the improvement of iron loading.

Davis et al in a study showed that administration of 24hour intravenous Deferoxaminewith appropriate dose via the catheter leads to improving serum ferritin condition and significantly reduces half the initial values. ${ }^{13}$

Wali and et al showed that one year after using high-dose intravenous Deferoxamine (200-240 mg per kg per day) with subcutaneous infusion through three days (every 10 hours), the serum ferritin and urinary excretion of iron (as a measure of iron overload) have decreased significantly. $^{15}$

According to the results of our study and those of other studies, intravenous Deferoxamine has positive effect on reducing serum ferritin amount (as the most important and accessible marker of iron overload in the body). ${ }^{9-11}$

Calvaruso et al showed that the Deferiprone shows same effectiveness and survival rate versus Deferoxamine with controlled safety profile and found the possibility of using this drug in thalassemia patients which was similar to our study results. ${ }^{21}$

Elalfy and et al in a study entitled "Efficacy and safety of a novel combination of two oral chelators Deferasirox/ Deferiprone over Deferoxamine/ Deferiprone in severely iron overloaded young beta thalassemia major patients" showed that both iron chelation combination regimens were equally effective in reducing iron overload and improving Quality Of Life. Deferoxamine/ Deferiprone combination proved superior in improving cardiac T2, treatment compliance, and patient's satisfaction with no greater adverse events. The results of our study disagree with their results. ${ }^{22}$

Xia et al in a meta-analysis showed that in comparing DFX with DFO, a significant difference was shown on SF level $(\mathrm{P}=0.003)$, and there was no difference between DFX and DFO in safety evaluation. The results of this study were similar to our results. ${ }^{20}$

\section{Limitation}

Because of ethical considerations we could not take healthy normal subjects as control group and so, the study had to be done as a quasi-experimental similar to beforeafter study in one group. Due to differences in dosage, duration, time of consuming and diet recommendations, it seems that more research with a larger sample size and longer follow-up period is needed in this area to achieve an exact evaluation of this regime.

\section{CONCLUSION}

Intravenous Deferoxamine concomitant use with monthly blood transfusion in thalassemia major patients leads to decreasing of serum ferritin, avoiding unpleasant subcutaneous Deferoxamine administration without any increasing in the complications. Therefore, by applied this method with adjusting dosage of Deferoxamine according to the decreasing rate of ferritin, we could effectively reduce health care costs, complications of treatment and finally improve patients care. Also, this method can be used in treatment of Splenectomized patients.

\section{Funding: No funding sources \\ Conflict of interest: None \\ Ethical approval: The study was approved by the Institutional Ethics Committee}

\section{REFERENCES}

1. Fisher SA, Brunskill SJ, Doree C, Gooding S, Chowdhury O, Roberts DJ. Desferrioxamine mesylate for managing transfusional iron overload in people with transfusion-dependent thalassaemia. Cochrane Database Syst Rev 2013;8:CD004450.

2. Cunningham MJ. Update on thalassemia: clinical care and complications. Hematol Oncol Clin North Am. 2010;24(1):215-27.

3. Weatherall DJ, Clegg JB. Inherited haemoglobin disorders: an increasing global health problem. Bull WHO. 2001;79(8):704-12.

4. Moradi GH, Ghaderi E. Chronic disease program in Iran: Thalassemia control program. Chron Dis J. 2013;1(2):98-106.

5. Saki N, Dehghani-Fard A, Kaviani S. Beta thalasemia: Epidemiology, diagnostic and treatment approach in Iran. Genet 3rd Millen. 2012;10(1):267583.

6. Abolghasemi H, Eshghi P. Comperehensive Textbook of Thalassemia, 1st ed, Iran. Medical University of Baghiatollah; 2004:189-201.

7. Orkin SH, Fisher DE, Look AT. Nathan and Oskì s Hematology of Infancy and Childhood. New York: Elsevier. 2009.

8. Piga A, Galanello R, Forni GL, Cappellini MD, Origa R, Zappu A, et al. Randomized phase II trial of deferasirox (Exjade, ICL670), a once-daily, orallyadministered iron chelator, in comparison to 
deferoxamine in thalassemia patients with transfusional iron overload. Haematologica. 2006;91(7):873-80.

9. Cappellini MD, Cohen A, Piga A, Bejaoui M, Perrotta S, Agaoglu L and et al. A phase 3 study of deferasirox (ICL670), a once-daily oral iron chelator, in patients with beta-thalassemia. Blood 2006;107(9):3455-62.

10. Laws HJ, Gobel U, Christaras A, Janssen G. Intensification of chelating-therapy in patients with thalassemia major. Klinische Pödiatrie. 2005;217(3):120-5.

11. Gamberini MR, De Sanctis V, Gilli G. Hypogonadism, diabetes mellitus, hypothyroidism, hypoparathyroidism: incidence and prevalence related to iron overload and chelation therapy in patients with thalassaemia major followed from 1980 to 2007 in the Ferrara Centre. Pediatr Endocrinol Rev. 2008;6(1):158-69.

12. Riaz H, Riaz T, Khan MU, Aziz S, Ullah F, Rehman A, et al. Serum ferritin levels, socio-demographic factors and desferrioxamine therapy in multitransfused thalassemia major patients at a government tertiary care hospital of Karachi, Pakistan. BMC Research Notes. 2011;4:287.

13. Davis BA, Porter JB. Long-term outcome of continuous 24-hour deferoxamine infusion via indwelling intravenous catheters in high-risk betathalassemia. Blood. 2000;95(4):1229-36.

14. Yarali N, Fişgin T, Duru F. Subcutaneous bolus injection of deferoxamine is an alternative method to subcutaneous continuous infusion. J Pediatr Hematol Oncol. 2006;28:11-6.

15. Wali YA, Taqi A, Deghaidi A. Study of intermittent intravenous deferrioxamine high-dose therapy in heavily iron-loaded children with beta-thalassemia major poorly compliant to subcutaneous injections. Pediatr Hematol Oncol. 2004;21(5):453-60.

16. Hagege I, Becker A, Kerdaffrec T. Long-term administration of high-dose deferoxamine 2 days per week in thalassemic patients. Eur $\mathbf{J}$ Haematol. 2001;67(4):230-1.

17. Tanner MA, Galanello R, Dessi C. A randomized, placebo-controlled, double-blind trial of the effect of combined therapy with deferoxamine and deferiprone on myocardial iron in thalassemia major using cardiovascular magnetic resonance. Circulation. 2007;115(14):1876-84.

18. Anderson LJ, Westwood MA, Holden S. Myocardial iron clearance during reversal of siderotic cardiomyopathy with intravenous desferrioxamine: a prospective study using T2 cardiovascular magnetic resonance. Br J Haematol. 2004;127(3):348-55.

19. Mashhadi MA, Rezvani AR, Naderi M, Moghaddam EM. The best iron chelation therapy in major thalassemia patients is combination of desferrioxamine and deferiprone. Int $\mathbf{J}$ HematolOncol Stem Cell Res. 2011;5(2):19-22.

20. Xia S, Zhang W, Huang L, Jiang H. Comparative efficacy and safety of deferoxamine, deferiprone and deferasirox on severe thalassemia: a meta-analysis of 16 randomized controlled trials. PLoS One. 2013;8(12):e82662.

21. Calvaruso G, Vitrano A, Di Maggio R. Deferiprone versus deferoxamine in thalassemia inter media: Results from a 5-year long-term Italian multicenter randomized clinical trial. Am J Hematol 2015;90(7):634-8.

22. Elalfy MS, Adly AM, Wali Y. Efficacy and safety of a novel combination of two oral chelatorsdeferasirox/ deferiprone over deferoxamine/ deferiprone in severely iron overloaded young beta thalassemia major patients. Eur J Haematol. 2015;95(5):411-20.

Cite this article as: Fathi A, Amani F, Araghchin S, Farzaneh E. Effect of intravenous Deferoxamine concomitant use with blood transfusion on serum ferritin in thalassemia major patients. Int J Basic Clin Pharmacol 2017;6:399-403. 